\title{
Pre-Task Planning Time Strategies for the Production of Request and Refusal Speech Acts in L2 English
}

\author{
Hadi Maghsoud ${ }^{1 *^{*}}$ \\ ${ }^{1}$ Faculty of Foreign Languages and Literatures, University of Tehran, Tehran, Iran \\ *Correspondence: Faculty of Foreign Languages and Literatures, University of Tehran, Tehran, Iran. E-mail: \\ hadi.maghsoud@gmail.com
}

Received: April 4, 2018

Accepted: May 13, 2018 Online Published: July 20, 2018

doi:10.5430/ijelt.v5n2p67

URL: https://doi.org/10.5430/ijelt.v5n2p67

\begin{abstract}
There is a growing consensus that implementation of planning time exerts an effect on oral speech production of learners. Research has yet to find out what strategies are used by learners in oral speech production. To contribute to this ongoing debate, the present study examined activation of sociopragmatic, pragmalinguistic, and content knowledge strategies employed by learners in pre-task planning time to produce answers. Ten M.A. students and Ph.D. candidates majoring in TEFL gave their answers to oral request and refusal DCTs through think-aloud protocol. The results revealed that the pre-task planning time caused the participants to activate a high degree of sociopragmatic, pragmalinguistic, and content knowledge awareness. Therefore, implementation of planning time in speaking tests may help individuals to produce more fluent and socially appropriate utterances.
\end{abstract}

Keywords: planning time, sociopragmatic, pragmalinguistic, content knowledge

\section{Introduction}

The last decade has evidenced a growing body of research on task-based language teaching (TBLT) and task performance. A plethora of studies have contributed to the field by addressing various issues regarding successful acquisition of language (e.g., Ellis, 2005; Philip, Oliver \& Mackey, 2006; Robinson, 2011). One of the most significant current discussions in TBLT and task performance has been time planning in performing pedagogical and authentic tasks. All types of speech production involve some extent of time planning regardless of their modality. Planning can be seen as a process which contributes to the production of speech and performance of speech acts. It can be seen as a solution which gives the speakers chance of filling the gaps of their speech (Ellis, 2005). "Planning is essentially a problem solving activity; it involves deciding what linguistic devices need to be selected in order to affect the audience in the desired way" (Ellis, 2005, p. 3). There is a growing consensus among scholars that planning time can improve speech production of the speakers (e.g., Gilabert, 2007; Ong, 2014; Skehan \& Foster, 1997; Wigglesworth, 1997; Wigglesworth \& Elder, 2010).

Gilabert (2007) investigated simultaneous manipulation of task complexity and planning time on oral speech production. He argued that task complexity exerts an influence on oral speech production and this complexity is by virtue of the amount of attention it demands. Skehan (Skehan, 1998; Skehan \& Foster, 2001) introduced a three-dimensional factor contributing to the difficulty of task which includes code complexity_vocabulary load and linguistic variety, cognitive complexity - schematic knowledge and topic familiarity, and communicative stress-power relationship, distance, and real time pressure. According to Skehan and Foster (2001) task manipulation effects should be studied in areas of complexity, accuracy, and fluency. To put it bluntly, Skehan and Foster investigated effect of time planning on accuracy, fluency, and complexity of produced oral speech of learners and concluded that exerted planning time leads to a more fluent and complex speech. Accuracy factor did not represent a considerable change but again they admitted that more research is needed before coming to a conclusion. Correspondingly, Gilabert (2007) reported a similar finding and asserted that time planning is very beneficial for oral speech production. 
A large body of research has focused on planning time in recent years. Ong (2014) conducted a study to investigate the effect of planning time and task conditions on metacognitive strategies used by L2 learners in their writing. She found that both planning time and task condition could influence task performance by L2 learners with more emphasis on the role of task condition. Li, Chen, and Sun (2014) investigated the effect of different lengths of planning time on the oral speech production. Applying discourse analytical measures, they interestingly found that planning time did have a significant effect on L2 learners' speech production. Amongst five different assigned lengths of time planning ( 30 seconds, 1 minute, 2 minutes, 3 minutes, and 5 minutes) 1 minute was the most effective one leading to significant improvement. Both too high and too low time planning had a negative impact on the learners' performance. Many other scholars conducted similar pieces of research on time planning and reported similar findings (for instance, Haizhen \& Fangqi, 2015; Markee \& Kunitz, 2013; Nielson, 2013; Philip, Oliver \& Mackey, 2006; Wigglesworth, 1997; Wigglesworth \& Elder, 2010).

Despite the rich amount of research on planning time in task performance, few studies have focused on activation of pragmalinguistic, sociopragmatic, and content sources of knowledge during planning time in oral speech production. Therefore, the current study aims to investigate whether the aforementioned sources of knowledge are activated during planning time.

\subsection{Studies on Planning Time}

There are grounds for supporting that planning time can exert a positive effect on oral speech production. Such was the case for Skehan and Foster's (2001) findings indicating that providing learners with enough planning time aids them in producing much more fluent and complex speech. Philip, Oliver and Mackey (2006) conducted a study to see how pre-task planning time influences oral speech production of children. They previously agreed on the positive effect of planning time on fluency and complexity of produced speech by adult L2 learners. Now the question was whether planning time also affected speech production of children. With this question in mind, they had children to perform three communicative tasks with different lengths of planning time for three consecutive weeks. They interestingly found that children's speech manifested a significant change in complexity and improved to a high extent. However, the improvement in complexity, accuracy and fluency manifested insignificant change.

Haizhen and Fangqi (2015) conducted a study in China to scrutinize the effect of different lengths of planning time on L2 learners' speech production. The study aimed at finding out whether planning time and proficiency affect performance. Learners in different groups were given different lengths of planning time. Their speech was recorded and subsequently rated by two trained raters. All groups s major improvement in their fluency. Syntactic complexity also increased in groups with more than 3 minutes of planning time. However, learners accuracy did not change considerably. Moreover, no relationship was observed between planning time and proficiency level of the learners. The findings were in line with some other pieces of research (e.g., Li, Chen, \& Sun, 2014; Skehan \& Foster, 2001).

Wigglesworth (1997) investigated the impact of planning time on speech production of L2 learners with different proficiency levels. He pointed out the beneficial aspects of planning time admitting limitation regarding its length in testing. The results suggested that exerted planning time had a positive influence on accuracy of learners with higher levels of proficiency. In contrast, low proficiency level learners did not show major improvement in their speech production. Moreover, Wigglesworth (1997) concluded that learners with high levels of proficiency manifested a considerable improvement in case of accuracy when they were given some planning time before producing speech. These findings were contradicted by many other studies (e.g., Haizhen \& Fangqi, 2015; Philip, Oliver \& Mackey, 2006; Skehan \& Foster, 2001). Later, in another study Wigglesworth and Elder (2010) investigated the influence of different lengths of planning time (0-2 minutes) on oral speech production in IELTS test but did not observe any considerable difference in the test takers' speech production. However, Wigglesworth and Elder suggested that there should be some planning time before speech production to improve test validity and fairness.

\subsection{Pragmalinguistic, Sociopragmatic, and Content Knowledge Sources}

During speech production a number of knowledge sources are activated, amongst which are pragmalinguistic, sociopragmatic, and content knowledge sources. According to Spencer-Oatey and Zegarac (2010) "pragmalinguistic perspective focuses on the linguistic strategies that are used to convey a given pragmatic meaning, while the sociopragmatic perspective focuses on the socially-based assessments, beliefs and interactional principles that underlie people's choice of strategies" (p. 76). A Pragmalinguistic perspective focuses in detail on the linguistic strategies utilized by individuals to 'operationalize' speech acts (e.g. requesting). On the other hand, the sociopragmatic convention deals with 'social judgments' of using linguistic forms (Spencer-Oatey \& Zegarac, 2010, p.76). 
Another important knowledge source activated by speakers is content knowledge. Shulman (1986) defines teacher content knowledge as "the amount and organization of knowledge per se in the mind of the teacher" (p. 9). Shulman argues that there are three types of content knowledge which are "(a) subject matter content knowledge, (b) pedagogical content knowledge, and (c) curricular knowledge" (p. 9). He further argues that the structure of content knowledge differs in different disciplines. Ball, Thames, and Phelps (2008) also assert that pedagogical content knowledge is a sophisticated concept with several definitions. They define pedagogical content knowledge as "a wide range of aspects of subject matter knowledge and the teaching of subject matter" (p. 389).

In the following section, a number of studies on pragmalinguistic and sociopragmatic strategies will be discussed. Content knowledge strategy is not subject of discussion due to its field-specific nature.

\subsection{Studies on Pragmalinguistic and Sociopragmatic Knowledge Sources}

Pragmatic ability is comprised of four main channels of communication, namely reading, writing, listening, and speech production (Cohen, 2010, p. 3). Speakers utilize a range of strategies during speech production. Amongst the main strategies employed by speakers are pragmalinguistic and sociopragmatic strategies. White (1993) investigated pragmalinguistic utterance production within politeness maxim by Japanese speakers. He attempted to find out why some grammatical utterances resulted in communication failure. The findings revealed that nonnative speakers were unware of the pragmatic context especially in cultural-specific utterances. Thus, pragmalinguistic failures happened due in part to use of grammatical but pragmatically inappropriate utterances.

Takahashi (2015) conducted a study on the effect of 'learner profiles' on understanding pragmalinguistic forms. Learners' pragmalinguistic advancement was assessed by oral discourse completion tasks. The results revealed that pragmalinguistic learning requires a deep understanding of instructed language and learner profiles were not effective in improving pragmalinguistic awareness. Riddiford and Holmes (2015) examined the effect of conscious learning and social interaction on sociopragmatic skills of immigrant speakers of English and observed improvement in participants' use of work place refusal. Chang (2011) conducted a study on the relationship between pragmalinguistic and sociopragmatic strategies and came to the conclusion that pragmalinguistic and sociopragmatic strategies are interrelated. A considerable number of studies have reported similar findings (e.g., Compernolle, 2011; Dascal, 1985; Felix-Brasdefer, 2008; Harlow, 1990; Holmes \& Marra, 2011; Karatepe, 2001; Spencer-Oatey \& Jiang, 2003; Vu, Bailey \& Howes, 2010).

There is no escaping the fact that vast majority of studies have been devoted to sociopragmatic and pragmalinguistic development of L2 learners. This is specifically true for some aspects of use of pragmalinguistic and sociopragmatic strategies. However, uncertainty still prevails as to what sociopragmatic, pragmalinguistic, and content knowledge sources are activated by L2 learners during pre-task planning time before speech production.

To fill in the gap, this study aims to investigate the sociopragmatic, pragmalinguistic, and content knowledge sources which are activated for production of refusal and request speech acts during pre-task phase planning time. As a result, the following research questions arise:

I. What pragmalinguistic knowledge sources do EFL learners activate to perform request and refusal speech acts?

II. What sociopragmatic knowledge sources do EFL learners activate to perform request and refusal speech acts?

III. What content knowledge sources do EFL learners activate to perform request and refusal speech acts?

\section{Method}

\subsection{Participants}

Ten M.A. students and Ph.D. candidates majoring in TEFL participated in this study. The participants were selected on a voluntary basis from both genders. Accuracy of responses, homogeneity of participants, and field-specific nature of responses requiring pragmatic knowledge were reasons for choosing the participants from amongst TEFL students. The participants' names were kept anonymous to ensure more genuine responses.

\subsection{Instruments}

Refusal Oral DCT: A two-item refusal DCT was used to elicit responses from the participants. The questions differed in terms of power status and distance.

Request Oral DCT: A two-item request DCT was administered to the participants. The questiones differed in terms of power status and distance. The first one elicited the answers observing low-high power relationship and the second one was concerned with equal power relation. 
Think-aloud protocol: To elicit the data using the DCTs, think-aloud protocol was implemented. The participants verbally stated all the pragmalinguistic, sociopragmatic, and content knowledge strategies that they would employ to answer the DCTs in pre-task planning time.

\subsection{Data Collection}

Each participant was asked to listen to the questions carefully and provide their answers after thinking for one minute. The whole process of data collocation was audio-taped by the researcher and subsequently transcribed for further analysis.

\subsection{Data Analysis}

To answer the first research question, the data was content analyzed to find the pragmalinguistic knowledge sources used by the participants to answer the questions. To find the answer for question two, the transcribed files were content analyzed to find out what sociopragmatic sources the participants activated to answer the DCT questions. For the last question, content analysis was performed to elicit the content knowledge sources activated by the participants to respond to the questions. Subsequently, the data was further analyzed to spot the differences between the answers to the DCTs in low-high and equal-equal power relations for each research question.

\section{Results}

Each research question was analyzed in detail by taking into account both refusal and request speech acts at both power level namely equal power relation and high-low power relation, also by considering the social distance and familiarity.

\subsection{Pragmalinguistic Knowledge Activation, Request Oral DCTs}

Regarding the first DCT in which the power relation was equal and the distance was close, majority of the participants preferred using an informal sentence instead of a sophisticated formal sentence to make a request. For instance, they used 'can' instead of 'could' and they made a direct request instead of an indirect one. Only a few patricipants used comparatively more polite and formal structures but none them made an indirect request. One of the participants said "Ali, would you please lend me your notes?" Then he added "because he is my close friend, I didn't add other markers." Another participant stated that "I would say, dear friend you have a book and I need it, can you give me your book?" he also mentioned that "he is my close friend!".

The second request DCT described a more formal situation. All the participants were aware of the formal situation and unequal power relation. This time, nearly all the participants employed a more formal linguistic structure to make their request. They chose to use 'could' or 'would' instead of 'can' and tried to make more polite remarks by adding markers like 'please'. For example, one of the participants said "I would appreciate if you could repeat your sentence" then she said that "he is my professor!". Another one said "Could you please speak more slowly?"

\subsection{Pragmalinguistic Knowledge Activation, Refusal Oral DCTs}

The first refusal oral DCT simulated a more informal situation with equal power relationship. Some of the participants told that they would simply refuse the request and use a direct informal sentence. For example, one of the participant told "sorry, But I need it myself". However, some of the participants asserted that refusing is a face threatening act and preferred to use a more indirect and formal structure. For instance, one said "You can barrow it from me next week" and added "I don't want my friend to think that I'm stingy and want to pile up my notes for myself, but first I have to apologize and give reason". Some of the participants preferred the first DCT and found it more justifiable and less face-threatening to the interlocutor. "I would say, I left the notes in my dormitory and I don't have access to them, then she will be disappointed and...that's it", said one of the participants. The other one justified telling a lie by saying "it's a white lie".

In the second refusal DCT the situation was more formal and the power relation was unequal. All of the participants utilized a more formal linguistic structure and tried to be indirect. They were more careful in vocabulary and structure selection. They also gave a couple of reasons for refusing the request. "He is my boss...!" said one of the participants. Another participant said that "I'm terribly sorry, I really liked to join you but I am busy at that time". Another one said that "I wouldn't refuse the request but I would propose another time". One of the participants said "I would say in a way that he/she become sad and take my job, I would say, sorry I'm busy with my job now and can't come, sorry". 


\subsection{Sociopragmatic Knowledge Activation, Request Oral DCTs}

Regarding the first DCT which represents an informal situation and equal power relation, majority of the participants used bald on records instead of off records. For instance, one of the participants said "Can I take your notes?" The other participant made it in this way "would you give me your notes?" and added "he is my close friend, I would be informal, I wouldn't use any mitigation". Another participant told "I just probably ask him using please you know...please give me that book, because my close friend you said...we are intimate, friendly relationship or politest think...would you...would you please give me that book?" He tried to be more friendly and attached to his close friend.

The second request DCT represented a more formal request situation with the power status of high-low. The participants were politer in making their requests and tried to use mitigation and more indirect sentences. "I will be more respectful, more polite, I would use would you mind repeating that, because he is my professor I should be more respectful". Another participant gave her answer in this way "is it possible to repeat it?". "pardon me, would you please repeat your sentence?" said another participant and then she added "we should use the polite request because of our professor". Almost all of the participants used politeness strategies to provide their answers to the second DCT. It would be better to say that nearly all of the participants were aware of the politeness strategies and situation demands. "he is my professor, the power relationship is high-low, the imposition is high and I should be more formal".

\subsection{Sociopragmatic Knowledge Activation, Refusal Oral DCTs}

The first refusal oral DCT, as was mentioned previously, represented an informal situation in which power relationship was equal. Majority of the participants responded in a clear informal manner. However, they were aware of the face threatening nature of refusal and gave more careful answers. For instance, one of the participants stated that "I will be polite and at the same time I will refuse the request because I am in need of that". She put the sentence in this way "sorry, I really wanted to lend my notebook but I...need it, so I can't...I am sorry". Because of prevailing intimacy and equal power relationship the participants used informal and simple sentences but again, tried to avoid face threatening act by using 'I am sorry', giving reasons and telling white lies.

The second refusal oral DCT, however, had a more formal nature and the situation was quite different, because the imposition was high and the power relationship was unequal (high-low). As a result, almost all of the participants used indirect sentences and mitigations. They gave a lot of explanation and tried to compensate for the refusal. One of the participants said "I'm not interested in that kind of gallery but he...he is my boss so I should say something that doesn't irritate him, because I want to continue my collaboration with him, I need him later on, so I would come up with a reason like an excuse. I would say there is a party...not a party it's not good, I would say my little brother got hit by car, I am going to go there and I cannot make it sorry". Another participant said "It is a formal case and I would be more polite, it is better to refuse with another excuse, I would say...sorry sir, but I have another important thing to do that I couldn't cancel it. I'm really sorry but... what about going there another time?" Majority of the answers to this DCT were longer and had a more sophisticated linguistic structure.

\subsection{Content Knowledge Activation, Request and Refusal Oral DCTs}

To answer both request and refusal oral DCTs, the participants utilized their content knowledge source. They used different linguistic structures in their responses based on the level of formality, social distance, and power. They knew how to use mitigation when the imposition was high. They were aware of face threatening acts and bald on records. Their pragmatic content knowledge sources helped them to produce appropriate, reasonable, and contextutterances to avoid communication failure, e.g. "I really liked to help out, but because the exams are approaching, I'm afraid I can't lend you my notes. Because it is a face threatening act, this feature is face threatening so I used some markers to mitigate this face threatening act".

\section{Discussion}

The aim of this study was to investigate the activation of sociopragmatic, pragmalinguistic, and content knowledge sources to prepare answers to oral DCTs in pre-task planning time by EFL learners. On balance, the findings indicated that the participants were aware of the context requirements and by activating their pragmatic content knowledge, they managed to produce appropriate answers.

Majority of the participants preferred using an informal and simple linguistic structure with intimate interlocutor and employed more formal and sophisticated structure in a formal situation. The social dimension was also well 
understood by the participants in that they produced socially acceptable utterances (e.g. using markers to mitigate face threatening act and keeping distance in formal situations).

Few concur with application of planning time in tests of speaking or oral production of language in classroom due to time constraint and practicality issues. However, in line with a number of studies, the findings of the present research indicate that it is worth to implement planning time in tests of oral speech production. Adding some more minutes to a test as planning time can assist individuals to come up with more fluent and structurally complex answers (Skehan $\&$ Foster, 2001). It also helps to improve validity and test fairness (Wigglesworth \& Elder, 2010).

\section{Conclusion}

The foregoing discussion attempted to examine the sociopragmatic, pragmalinguistic, and content knowledge strategies in pre-task planning time for oral speech production. It is hard to escape the obvious conclusion that implementing pre-task planning time may boost activation of sociopragmatic, pragmalinguistic, and content knowledge strategies and increase test validity and fairness (Wigglesworth \& Elder, 2010). This study was an in-depth investigation of use of sociopragmatic, pragmalinguistic, and content knowledge strategies; therefore, caution should be exercised regarding generalizability of the results. There also remains room for further research on gender-based use of strategies by the learners. The question may be whether gender influences utilization of sociopragmatic, pragmalinguistic, and content knowledge sources in oral speech production. The study can also be replicated using other speech acts to produce answers.

\section{References}

Ball, D. L., Thames, M. H., \& Phelps, G. (2008). Content knowledge for teaching: What makes it Special? Journal of Teacher Education, 59(5), 389-407. https://doi.org/10.1177/0022487108324554

Chang, Y. (2011). Interlanguage pragmatic development: The relation between pragmalinguistic competence and sociopragmatic competence. Language Science, 33, 786-798. https://doi.org/10.1016/j.langsci.2011.02.002

Cohen, A. D. (2010). Coming to terms with pragmatics. In N. Ishihara \& A. D. Cohen (Eds.), Teaching and learning pragmatics: Where language and culture meet (pp. 3-20). London, UK: Pearson.

Compernolle, R. A. V. (2011). Developing second language sociopragmatic knowledge through concept-based instruction: A microgenetic case study. Journal of Pragmatics, 43, 3267-3283. https://doi.org/10.1016/j.pragma.2011.06.009

Dascal, M. (1985). Language use in jokes and dreams: Sociopragmatic vs psychopragmatics. Language \& Communication, 5(2), 95-106. https://doi.org/10.1016/0271-5309(85)90002-3

Ellis, R. (2005). Planning and task-based performance: Theory and research. In R. Ellis (Ed.), Planning and task performance in a second language (pp. 3-34). Philadelphia, US: John Benjamins. https://doi.org/10.1075/1llt.11

Felix-Brasdefer, J. C. (2008). Sociopragmatic variation: Dispreferred responses in Mexican and Dominican Spanish. Journal of Politeness Research, 4, 81-110. https://doi.org/10.1515/PR.2008.004

Gilabert, R. (2007). The simultaneous manipulation of task complexity along planning time and [/ here-and-now]: Effects on L2 oral production. In M. P. García Mayo (Ed.), Investigating tasks in formal language learning (pp. 44-68). Toronto, Canada: Multilingual Matters LTD.

Haizhen, W., \& Fangqi, S. (2015). Effects of strategic planning time on L2 paired oral test performance. Chinese Journal of Applied Linguistics, 38(3), 263-276.

Harlow, L. L. (1990). Do they mean what they say? Sociopragmatic competence and second language learners. The Modern Language Journal, 74, 327-351. https://doi.org/10.1111/j.1540-4781.1990.tb01070.x

Holmes, J., \& Marra, M. (2011). Harnessing storytelling as a sociopragmatic skill: Applying narrative research to workplace English courses. TESOL Quarterly, 45(3), 510-535. https://doi.org/10.5054/tq.2011.256796

Karatepe, C. (2001). Pragmalinguistic awareness in EFL teacher training. Language Awareness, 10(2\&3), 176-188. https://doi.org/10.1080/09658410108667033

Li, L., Chen, J., \& Sun, L. (2015). The effects of different lengths of pretask planning time on L2 learners' oral test performance. TESOL Quarterly, 49(1), 38-66. https://doi.org/10.1002/tesq.159 
Markee, N., \& Kunitz, S. (2013). Doing planning ad task performance in second language acquisition: An ethnomethodological respecification. Language Learning Research Club, 1-36. https://doi.org/10.1111/lang.12019.

Nielson, K. B. (2014). Can planning time compensate for individual differences in working memory capacity? Language Teaching Research, 18(3), 272-293. https://doi.org/10.1177/1362168813510377

Ong, J. (2014). How do planning time and task conditions affect metacognitive processes of L2 writers? Journal of Second Language Writing, 23, 17-30. https://doi.org/10.1016/j.jslw.2013.10.002

Philip, J., Oliver, R., \& Mackey, A. (2006). The impact of planning time on children's task-based interactions. System, 34, 547-565. https://doi.org/10.1016/j.system.2006.08.004

Riddiford, N., \& Holmes, J. (2015). Assisting the development of sociopragmatic skills: Negotiating refusals at work. System, 48, 129-140. https://doi.org/10.1016/j.system.2014.09.010

Robinson, P. (2011). Task-based language learning: A review of issues. In P. Robinson (Ed.), Task-based language learning (pp. 1-36). Oxford: Wiley Blackwell. https://doi.org/10.1111/j.1467-9922.2011.00641.x

Shulman, L. S. (1986). Those who understand: Knowledge growth in teaching. Educational Researcher, 15(2), 4-14. https://doi.org/10.3102/0013189X015002004

Skehan, P. (1998). A cognitive approach to language learning. Oxford: Oxford University Press.

Skehan, P., \& Foster, P. (1997). Task type and task processing conditions as influences on foreign language performance. Language Teaching Research, 1(3), 185-211. https://doi.org/10.1177/136216889700100302

Skehan, P., \& Foster, P. (2001). Cognition and tasks. In P. Robinson (Ed.), Cognition and second language instruction (pp. 183-205). Cambridge: Cambridge University Press. https://doi.org/10.1017/CBO9781139524780.009

Spencer-Oatey, H., \& Jiang, W. (2003). Explaining cross-cultural pragmatic findings: Moving from politeness maxims to sociopragmatic interactional principles (SIPs). Journal of Pragmatics, 35, 1633-1650. https://doi.org/10.1016/S0378-2166(03)00025-0

Spencer-Oatey, H., \& Zegarac, V. (2010). Pragmatics. In N. Schmitt (Ed), An introduction to applied linguistics (2 ${ }^{\text {nd }}$ ed.) (pp. 70-88). London, UK: Hodder \& Stoughton Ltd.

Takahashi, S. (2015). The effects of learner profiles on pragmalinguistic awareness and learning. System, 48, 48-61. https://doi.org/10.1016/j.system.2014.09.004

Vu, J. A., Bailey, A. L., \& Howes, C. (2010). Early cases of code-switching in Mexican-heritage children: Linguistic and sociopragmatic considerations. Bilingual Research Journal, 33, 200-219. https://doi.org/10.1080/15235882.2010.502798

White, R. (1993). Pragmalinguistic failure in English interaction. ELT Journal, 47(3), 193-202. https://doi.org/10.1093/elt/47.3.193

Wigglesworth, G. (1997). An investigation of planning time and proficiency level on oral test discourse. Language Testing, 14(1), 85-106. https://doi.org/10.1177/026553229701400105

Wigglesworth, G., \& Elder, C. (2010). An investigation of the effectiveness and validity of planning time in speaking test tasks. Language Assessment Quarterly, 7(1), 1-24. https://doi.org/10.1080/15434300903031779

\section{Appendix}

\section{Request DCTs:}

1. You are working on an assignment you know that your close friend has a book which is quite helpful for this assignment. You decide to ask your friend to lend you the book. What would you say?

2. You are now discussing your assignment with your teacher/professor. Your teacher/professor speaks very fast. You do not follow what he is saying. You want to ask your teacher to say it again. What would you say? 


\section{Refusal DCTs:}

1. You are a junior in college. You attend classes regularly and take good notes. Your classmate often misses class and asks you for the lecture notes. However, you need the notes yourself and wouldn't lend them to her, so you refuse her request. What would you say?

2. You are going to refuse an invitation offered to you by your boss to an art gallery. What would you say? 